\title{
EVALUATION OF SELF-INFLATING SOFT TISSUE EXPANDERS PRIOR TO VERTICAL RIDGE AUGMENTATION IN ATROPHIC POSTERIOR MANDIBLE
}

\author{
Salah El-Abbasy *
}

\begin{abstract}
Aim: To evaluate the self-inflating tissue expander prior to vertical ridge augmentation of atrophic posterior mandible.

Materials and methods: Eight patients with atrophic posterior mandible were included in the study. Self-inflating tissue expander was inserted in a submucosal pouch and removed after 60 days. Vertical ridge augmentation was performed using sandwiched graft technique with allogenic bone blocks.

Results: No signs of inflammation or thinning of the mucosa was observed. None of the patients were presented with any dehiscence or graft exposure during different follow up periods. The height of the bone blocks used was measured with a periodontal probe for all the patients after insertion in the surgical site with a mean vertical height gain of $8.36 \pm 1.63 \mathrm{~mm}$. The mean soft tissue volume gain according to the measurements obtained from the optical analysis was $834.4 \pm 59 \mathrm{~mm} 3$
\end{abstract}

Conclusion: Self-inflating tissue expanders combined with sandwiched vertical ridge augmentation procedure in posterior atrophic mandibles showed excellent results regarding healing, absence of inflammation, adequate soft tissue and hard tissue gain with absence of any signs of dehiscence or graft exposure.

KEYWORDS: Self-inflating tissue expanders, Sandwiched graft technique

\section{INTRODUCTION}

Implant placement in an atrophic posterior mandible is a hard challenge for the dental surgeons due to lack of adequate soft and hard tissues. ${ }^{1}$ Many surgical techniques were introduced to augment the posterior mandible including guided bone regeneration, distraction osteogenesis, onlay bone grafting and interpositional bone grafts. ${ }^{2,3,4}$

Bony reconstruction of large defects is usually associated with high complication rates due to

* Lecturer of Oral and Maxillofacial Surgery, Oral and Maxillofacial Surgery Department, Faculty of Dentistry, Cairo University 
inadequate soft tissue quantity to cover the graft which make it impossible to achieve tension-free wound closure leading to wound dehiscence and graft exposure followed by partial or total loss of the graft. ${ }^{5,6,7}$ To overcome this problem, periosteal incisions are usually performed to enable stretching and mobilizing the flap, however this compromises the blood flow of the flap and reduce tissue perfusion..$^{5,8-10}$

Soft tissue expanders have been introduced to increase the soft tissue volume prior to the grafting procedures. ${ }^{11,12,13}$ After insertion of the expanders, it gradually increases in volume causing tension on the surrounding tissues and finally results in tissue gain. ${ }^{14,15}$

Unlike balloon expanders which require leaving a one way valve outside the soft tissue tunnel which leads to inflammation and infection, the Osmotic self-filling expanders are formed of a polymer surrounded with a silicone shell having pores that allows the influx of tissue fluids gradually and continuously with decreased risk of inflammation or infection. ${ }^{16,17}$

The combination between tissue expanders and subsequent ridge augmentation reduces the graft exposure risk by $25 \%$ and provides a well-structured bone for a successful implant procedure. ${ }^{11}$

\section{MATERIALS AND METHODS:}

Eight patients with atrophic posterior mandible in need of vertical ridge augmentation of more than $4 \mathrm{~mm}$ with insufficient amount of soft tissues were included in this study. All the patients selected were free from any local or systemic disease that may complicate the healing process. The patients were asked to sign a written consent of approval to participate in our study.

\section{Placement of the tissue expander:}

An alginate impression was taken for all the patients prior to any surgical procedure.
Surgeries were performed under local anaesthesia 4\% Articaine hydrochloride with epinephrine 1:100,000. A vertical incision was performed mesial to the defect and the tissues were undermined using a metzenbaum scissor to create a submucosal pouch of adequate size to allow insertion of the tissue expander.

Self-inflating tissue expander (Osmed, Ilmenau, Germany) with initial volume of $250 \mathrm{~mm}^{3}$ was placed inside the created pouch and fixed in place with a monocortical screw (Fig.1) and the wound was sutured using 3-0 black silk sutures.

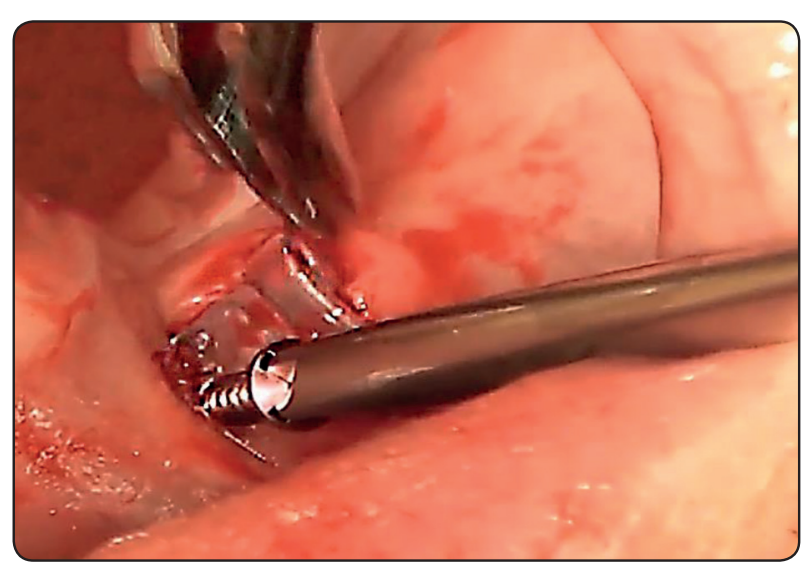

Fig. (1) Showing the insertion and fixation of the tissue expander inside the pouch with a miniscrew.

The tissue expander was left in place for 60 days according to the manufacturer's instruction to reach its final volume then it was removed during the vertical ridge augmentation procedure.

\section{Expander removal and ridge augmentation:}

After the soft tissue expantion procedure was successfully completed, a preoperative alginate impression was taken for all the patients then the ridge augmentation procedure was performed under local anaesthesia 4\% Articaine hydrochloride with epinephrine 1:100,000. A Paracrestal incision was carried out followed by flap reflection avoiding any tension on the mental nerve. The fixation screw and the expander were removed from the tissue pouch 
(Fig. 2). The surface of the underlying bone was examined to check for any resorption that might occur due to pressure from the tissue expander.

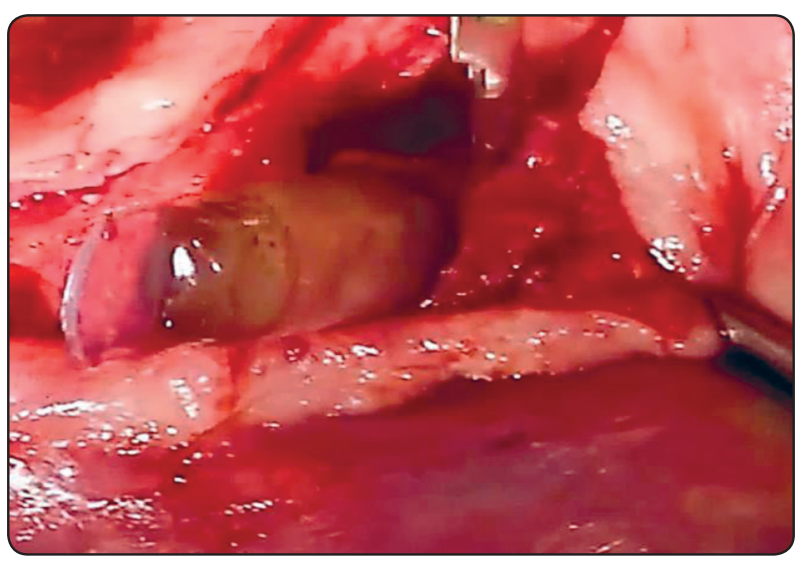

Fig. (2) Showing removal of the tissue expander from the tissue pouch

A horizontal osteotomy was carried out 5 $\mathrm{mm}$ above the inferior alveolar nerve using the conventional rotary instruments. Mesial and distal oblique osteotomies were performed placing the mesial osteotomy at least $2 \mathrm{~mm}$ away from the adjacent tooth. The separation of the bone segment was completed using bone chisels and the bone segment was elevated with preservation of the lingual mucoperiosteum.

An allogenic bone block (Puros ,Zimmer Dental, USA) was remodeled according to the desired width and height and was placed between the elevated crestal bone segment and the basal bone of the mandible (Fig.3). The crestal bone segment and the mandibular basal bone were fixed together using miniplates and screws. Bioss graft material (BioOss® ${ }^{\circledR}$, Geistlich Pharma, Wolhusen, Switzerland) was used to fill any spaces between the bone block and the mandibular bone. The grafted bone was covered with a membrane (Bio-Gide ${ }^{\circledR}$, Geistlich Pharma,Wolhusen, Switzerland) and the flap was easily sutured in place using 3-0 black silk suture without any tension.

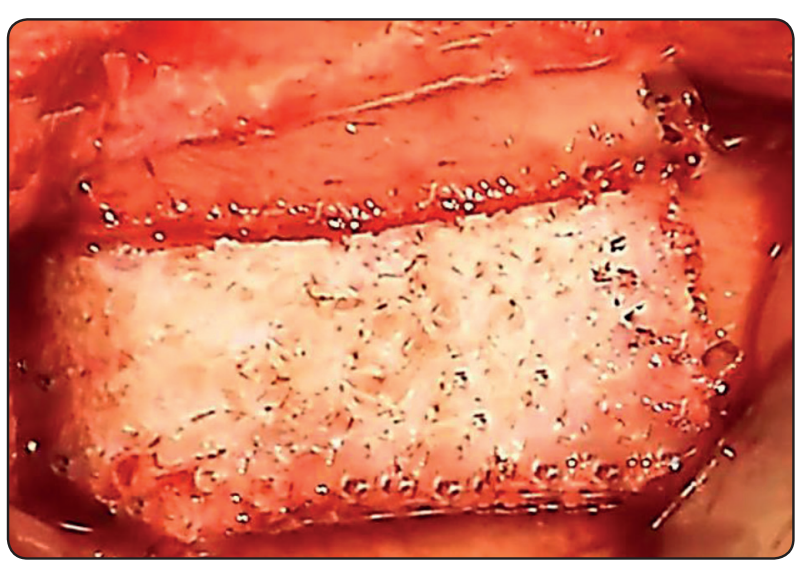

Fig. (3) Showing bone block sandwiched between the crestal bone and the basal bone of the mandible.

Postoperative antibiotic Clindamycin $\mathrm{HCl} 300$ mg tablets every 8 hours for 5 days, Ketoprofen 50 $\mathrm{mg}$ analgesic tablets three times daily for 3-5 days, mouth rinsing with $0.12 \%$ Chlorohexidine gluconate 3 times per day for 7 days were prescribed for all the patients following both surgical procedures.

Follow up in terms of healing, infection, dehiscence, membrane exposure and graft expulsion was performed after 1 week and 2 months postoperatively.

\section{Optic Scanning volumetric analysis:}

Volumetric analysis was previously decribed by Shneider et al ${ }^{18}$ and Thalmair et al ${ }^{19}$. Alginate impressions were taken for all the patients before insertion of the expander and after 60 days from the expansion procedure. Casts were obtained from the impressions and were scanned using an optical scanner (Cerec 3D, Sirona Dental Systems GmbH, Bensheim, Germany) and the images obtained were imported to the CAD software Geomagic Studio ${ }^{\circledR}$ 2013, Raindrop Geomagic, NC, USA). Both images were superimposed over each other and the volume difference in the expansion area was calculated (Fig.4, 5, 6, 7, 8). Follow up in terms of healing, infection, dehiscence, membrane exposure and graft expulsion was performed after 1 week and 2 months from the grafting procedure. 


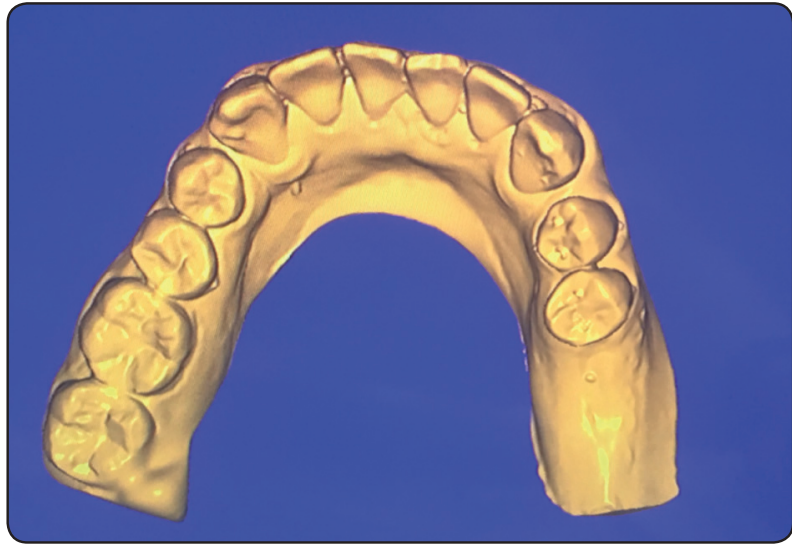

Fig. (4) Showing occlusal view for scanned preoperative cast

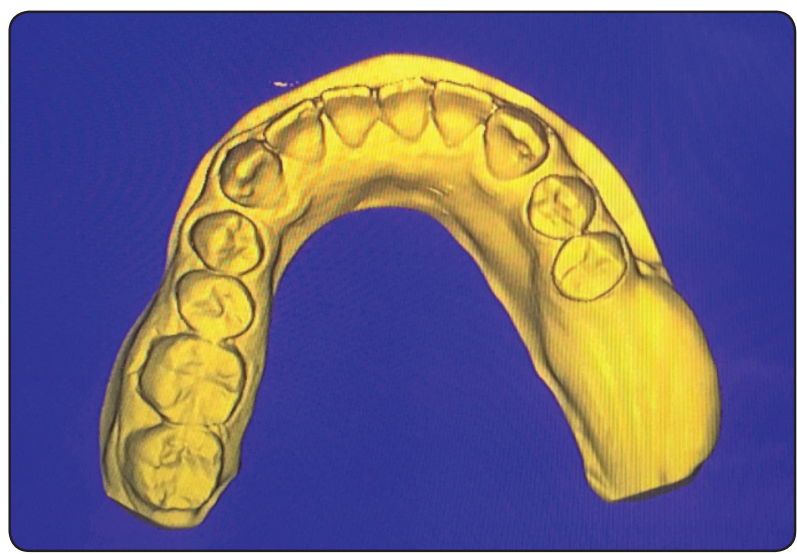

Fig. (6) Showing occlusal view of scanned cast obtained after 60 days from the tissue expansion procedure.

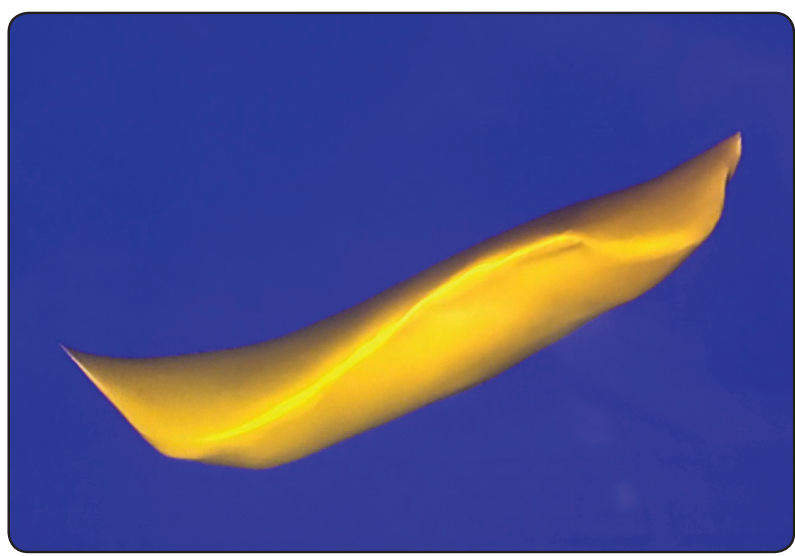

Fig. (8) Showing the volumetric difference in expansion area preoperatively and after 60 days following the expansion procedure.

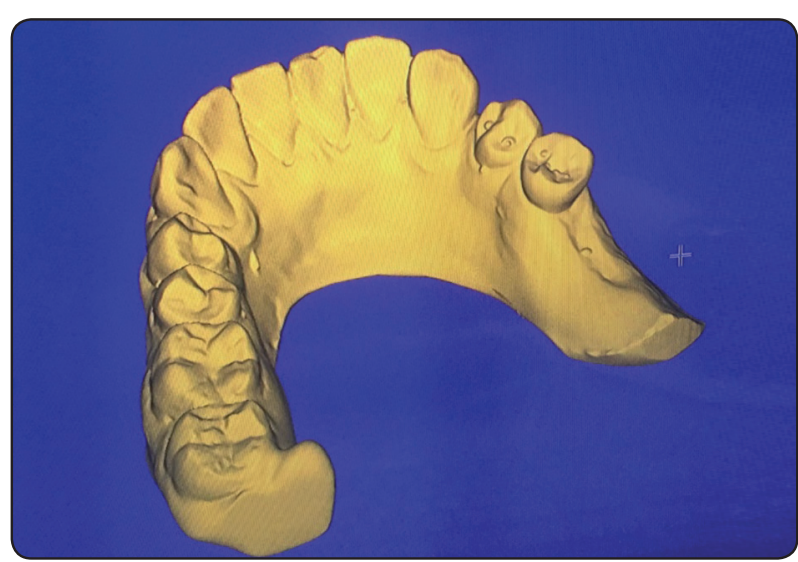

Fig. (5) Showing angled view for scanned preoperative cast of the atrophic posterior mandible.

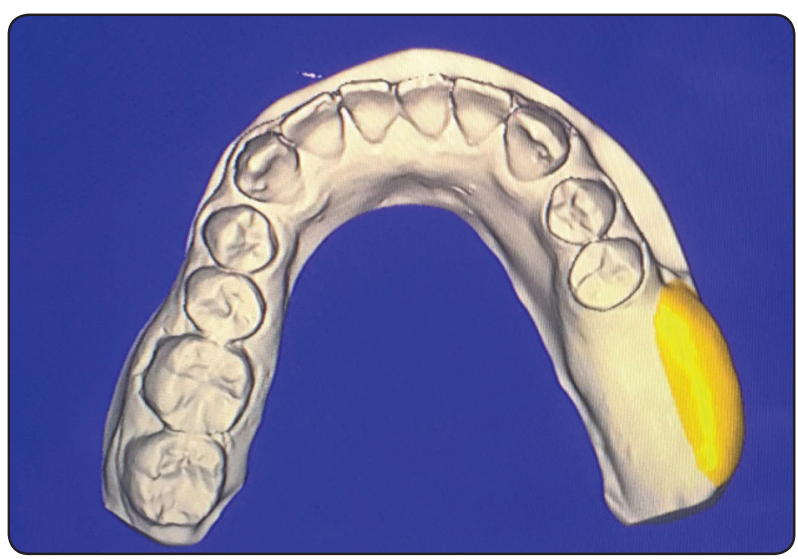

Fig. (7) Showing Superimposition of both casts with highlighting the difference in the expansion area.

\section{RESULTS}

Eight patients (6 males and 2 females) with an age range of 44-61 years and a mean age of $51.7 \pm 6.1$ years were included in the study. One patient was excluded from the study due to rupture of the expander after 29 days due to wearing a removable prosthetic device by the patient although being instructed not to do so. Seven patients completed the study till the end of the grafting procedure.

Following the surgical procedures, no signs of infection or thinning of the mucosa was observed. None of the patients were presented with any 
dehiscence or graft exposure during different follow up periods.

The soft tissue expander used for all the patients had an initial volume of $250 \mathrm{~mm} 3$ that reached $1300 \mathrm{~mm} 3$ after placement in the surgical site for 60 days according to the manufacturer's data. Following the removal of the expander from the surgical site, the underlying bone was examined and no signs of resorption was visualized.

Following the augmentation procedure, suturing was easily achieved without any tension and without cutting through the periosteum or performing vertical releasing incisions.

The height of the bone blocks used was measured with a periodontal probe for all the patients after insertion in the surgical site with a mean vertical height gain of $8.36 \pm 1.63 \mathrm{~mm}$.

The mean soft tissue volume gained according to the measurements obtained from the optical analysis of the preoperative cast and the cast obtained after 60 days following the expansion procedure was $834.4 \pm 59 \mathrm{~mm} 3$.

\section{DISCUSSION}

In our study, no signs of infection or thinning and blanching of the mucosa was observed following the insertion of the self-inflating tissue expander until removal after 60 days. This agrees with Ronert et al ${ }^{16}$ reporting that less infection resulted with self-filling expanders when compared to the balloon filling expanders due to elimination of the need for a filling valve passing out from the surgical pouch which can easily get contaminated leading to infections.

In the present study, self-inflating tissue expanders resulted in safe, gradual and continuous expansion of the soft tissues without any signs of hypoxia in the overlying mucosa. This is in contrast with the findings of Pietila ${ }^{20}$, Wiese ${ }^{21}$ and Anwander et al ${ }^{17}$ who reported that the injection dependent pressure peaks that occur with the use of inflatable balloon expanders decreases the tissue perfusion and may result in hypoxia and tissue necrosis following the weekly injection of saline..

In the present study, none of patients were presented with soft tissue dehiscence or graft exposure to the oral cavity and this is attributed to the availability of adequate soft tissue quality and quantity following the expansion procedure without any difficulties during the suturing process. This agrees with the study of Cordaro et al ${ }^{22}$, Felice et al ${ }^{23}$ and Urban et al ${ }^{24}$ reporting that ridge augmentation procedures are associated with up to $50 \%$ graft exposure and attributed this to the lack of adequate soft tissue quantity and suturing under tension, hence comprising the flap's vascularity which results in dehiscence and graft exposure.

In our study, submucosal insertion of the expander was performed to avoid any pressure over the underlying bone and no signs of underlying bone resorption were observed in any patient following the removal of the expander. This coincides with the findings of Stuehmer et al ${ }^{25}$ and Kaner and Friedmann ${ }^{11}$ who reported a significantly less bone resorption associated with submucosal insertion of the tissue expander when compared to subperiosteal insertion of the expander.

In the current study, the final volume of the expanders after 60 days according to the manufacturer's data is $1300 \mathrm{~mm}^{3}$; however, the mean soft tissue volume gained in the tissues according to the measurements obtained from the optical analysis was $834.4 \pm 59 \mathrm{~mm} 3$. Kaner and Friedmann ${ }^{11}$ reported that the final soft tissue gain may be affected by whether the expander was placed subperiosteal or submucosal, however these results should be confirmed in future studies.

In this study, the Sandwiched bone graft was the technique selected for the vertical ridge augmentation procedure. No dehiscence or graft exposure occurred in any patient. This agrees with 
previous studies $26,27,28,29$ reporting that adequate graft stability is achieved with the sandwiched graft technique together with significantly less dehiscence and graft exposure when compared to onlay grafts and grafts utilizing titanium mesh.

\section{CONCLUSION}

Self-inflating tissue expanders combined with sandwiched vertical ridge augmentation procedure in posterior atrophic mandibles showed excellent results regarding healing, absence of infection, adequate soft tissue and hard tissue gain with absence of any signs of dehiscence or graft exposure.

\section{REFERENCES}

1- Constantin Von See, Nils-Claudius Gellrich, Ulrike Jachmann, Matthias W. Laschke, Kai-Hendrik Bormann, Martin Rucker. Bone augmentation after soft tissue expansion using hydrogel expanders:effects on microcirculation and osseointergration,Journal of Periodontol; 8: 842-847, 2010.

2- M. Simion, S. A. Jovanovic, C. Tinti, and S. P. Benfenati. Long term evaluation of osseointegrated implants inserted at the time or after vertical ridge augmentation: a retrospective study on 123 implants with 1-5 year follow-up. Clinical Oral Implants Research; 1: 35-45, 2001.

3- J. H. Fu, T. J. Oh, E. Benavides, I. Rudek, and H. L. Wang. A randomized clinical trial evaluating the efficacy of the sandwich bone augmentation technique in increasing buccal bone thickness during implant placement surgery: I. Clinical and radiographic parameters. Clinical Oral Implants Research; 25: 458-467, 2014.

4- S.-H. Park, K.-W. Lee, T.-J. Oh, C. E.Misch, J. Shotwell, and H.- L. Wang. Effect of absorbable membranes on sandwich bone augmentation. Clinical Oral Implants Research; 19: 32-41, 2008.

5- Esposito M, Grusovin MG, Maghaireh H, Coulthard P, Worthington HV. Interventions for replacing missing teeth: management of soft tissues for dental implants. Cochrane Database Syst Rev; 3:CD006697, 2007.

6- Proussaefs P, Lozada J. The use of intraorally harvested autogenous block grafts for vertical alveolar ridge augmentation: a human study. Int J Periodontics Restorative Dent; 25:351-363, 2005 .
7- Roccuzzo M, Ramieri G, Bunino M, Berrone S. Autogenous bone graft alone or associated with titanium mesh for vertical alveolar ridge augmentation: a controlled clinical trial. Clin Oral Implants Res; 18:286-294, 2007.

8- Lundgren S, Sjostrom M, Nystrom E, Sennerby L. Strategies in reconstruction of the atrophic maxilla with autogenous bone grafts and endosseous implants. Periodontology 2000; 47:143-161, 2008.

9- Jivraj S, Chee W. Treatment planning of implants in the esthetics zone. Br Dent J; 201:77-89, 2006.

10- Rothamel D, Schwarz F, Herten M, Ferrari D, Mischkowski RA, Sager M, Becker J. Vertical ridge augmentation using xenogenous bone blocks: a histomorphometric study in dogs. Int J Oral Maxillofac Implants; 24:243-250, 2009.

11- D. Kaner and A. Friedmann. Soft tissue expansion with self-filling osmotic tissue expanders before vertical ridge augmentation: a proof of principle study. Journal of Clinical Periodontology; 38: 95-101, 2011.

12- P. Abrahamsson, D. A. W“alivaara, S. Isaksson, and G. Andersson. Periosteal expansion before local bone reconstruction using a new technique for measuring soft tissue profile stability: a clinical study. Journal of Oral and Maxillofacial Surgery; 70: e521-e530, 2012.

13- C. Mertens, O. -iele, M. Engel, R. Seeberger, J. Hoffmann, and K. Freier. Use of self-inflating soft tissue expanders prior to bone augmentation of atrophied alveolar ridges. Clinical Implant Dentistry and Related Research; 17:44$51,2015$.

14- Bennet RG, Hirt M. A history of tissue expansion. Concepts, Controversies and Complications. J Dermatol Surg Oncol; 19: 1066-73,1993.

15- Bascon DA, Wax KA. Tissue expansion in head and neck: Current state of the art. Curr Opin Otolaryngol Head Neck Surg;10:273-7, 2002.

16- Ronert MA, Hofheinz H, Manassa E, Asgarouladi H, Olbrisch RR. The beginning of new era in tissue expansion: Self filling osmotic tissue expander-four year clinical experience. Plast Reconstruct Surg; 114:1025-31, 2004.

17- Anwander T, Schneider M, Gloger W, Reich RH, Appel T, Martini M, et al. Investigation and expansion properties of osmotic expanders with and without silicone shells in animals. Plast Reconstr Surg; 120:590-5, 2007.

18- D. Schneider, U. Grunder, A. Ender, C. H. H“ammerle, and R.E. Jung. Volume gain and stability of peri-implant tissue 
following bone and soft tissue augmentation: 1-year results from a prospective cohort study. Clinical Oral Implants Research; 22: 28-37, 2011.

19- T. Thalmair, S. Fickl, D. Schneider, M. Hinze, and H. Wachtel. Dimensional alterations of extraction sites after different alveolar ridge preservation techniques-a volumetric study. Journal of Clinical Periodontology; 40: 721-727, 2013.

20- Pietila, J. P. Tissue expansion and skin circula-tion. Simultaneous monitoring by laser Doppler flowmetry and transcutaneous oximetry. Scandinavian Journal of Plastic and Reconstructive Surgery and Hand Surgery; 24 :135140, 1990.

21- Wiese, K. G. Osmotically induced tissue expansion with hydrogels: a new dimension in tissue expansion? A preliminary report. Journal of Craniomaxillofacial Surgery; 21: 309-313, 1993.

22- Cordaro L, Amadé DS, Cordaro M. Clinical results of alveolar ridge augmentation with mandibular block bone grafts in partially edentulous patients prior to implant placement. Clin Oral Implants Res;13:103-11, 2002.

23- Felice P., Marchetti C., Iezzi G., Piattelli A., Worthington H., Pellegrino G., Esposito M. Vertical ridge augmentation of the atrophicposterior mandible with interpositional bloc grafts: bone from the iliac crest vs. bovine anorganic bone. Clinical and histological results up to one year after loading from a randomized-controlled clinical trial. Clinical Oral Implants Research; 20: 1386-1393, 2009.
24- Urban, I. A., Jovanovic, S. A. \& Lozada, J. L. Vertical ridge augmentation using guided boneregeneration (GBR) in three clinical scenarios prior to implant placement: a retrospective study of 35 patients 12 to 72 months after loading. The Inter-national Journal of Oral \& Maxillofacial Implants; 24 : 502-510, 2009.

25- Stuehmer, C., Rucker, M., Schumann, P., Bormann, K.H., Harder, Y., Sinikovic, B. \& Gellrich, N. C. Osseous alterations at the interface of hydro-gel expanders and underlying bone. Journal of Craniomaxillofacial Surgery; 37:258-262, 2009.

26- C.Marchetti, S. Trasarti, G. Corinaldesi, and P. Felice. Interpositional bone grafts in the posteriormandibular region: a report on six patients. The International Journal of Periodontics and Restorative Dentistry; 27: 547-555, 2007.

27- A. Bianchi, P. Felice, G. Lizio, and C. Marchetti. Alveolar distraction osteogenesis versus inlay bone grafting in posterior mandibular atrophy: a prospective study. Oral Surgery, Oral Medicine, Oral Pathology, Oral Radiology and Endodontology; 105: 282-292, 2008.

28- A. Laviv,O. T. Jensn, E. Tarazi, andN.Casap. Alveolar sandwich osteotomy in resorbed alveolar ridge for dental implants: a 4 year prospective study. Journal of Oral and Maxillofacial Surgery; 72: 292-303, 2014.

29- P. Felice, C.Marchetti, A. Piattelli et al. Vertical ridge augmentation of the atrophic posterior mandible with interpositional block grafts: bone from the iliac crest versus bovine anorganic bone. European Journal of Oral Implantology; 1: 183-198, 2008. 